\title{
Demands Analysis for the Central Business District Building Projects Based on Quality Function Deployment
}

\author{
Shuang ZHANG \\ School of Mechanics, Civil Engineering and Architecture, Northwestern Polytechnical University (NPU), \\ Xi'an, P. R. China
}

\begin{abstract}
For the large Central Business District (CBD) building project portfolio, it is particularly important how to accurately analyze the project task needs. The entropy method was introduced to the traditional model of Quality Function Deployment (QFD), to process the ambiguity of the data caused by the incomplete information. At first, the weight of user demands indicators were determined and the relationships between the various indicators were analyzed by the QFD, and the demands characteristics were converted to the technical characteristics. Secondly, the weights and correlation of the technical characteristics were determined, and the user demands were more comprehensively, objectively and realistically converted to the characteristics of the product. At last, a development example of the CBD building project portfolio was introduced to explain the practicability and reliability of the model and method.
\end{abstract}

KEYWORD: Central Business District (CBD); Demands Analysis; Project Management; Quality Function Deployment (QFD); Entropy

\section{INTRODUCTION}

As the modern symbol and logo of a city, the Central Business District (CBD) is the functional core of the city. It is a concentrated area of the city economic, scientific, technological, cultural, and generally locates on the city's golden mile. The projects need lots of facilities, to meet the following features of finance, commerce, culture, services, as well as a large number of business travellers and hotels, apartments and so on. At the same time, it requires the most sophisticated transportation, communications, other modern infrastructure and a sound environment to meet a large number of businesses, financial institutions, corporate groups where a wide range of business activities. In the process of development and construction, due to complex factors and factors of decomposition, tradeoffs, comprehensive transformation, convergence and mutual relationship, also due to reasons such as environment and stakeholders expressed, builders often do not fully develop the effective information. Therefore, the project's mission requirements must be accurately analyzed. As the method that converts the user requirement to product characteristics, Quality Function Deployment (QFD) has been widely used in the field of product research and development. Due to incompleteness and vagueness of project information, the traditional QFD are difficult to convert the real user needs to the technical characteristics of the product, therefore the entropy method is introduced.

\section{THE QFD MODEL BASED ON ENTROPY}

The main idea of QFD is: in the product development process, all activities are driven by user needs, preferences and expectations, to ensure our products meet the user needs [1]. To establish the model of QFD, the key and difficult point is to determine the needs of users, and determine its importance and its relation with technical characteristics. Expressed in deterministic numerical sequence, the traditional method was determined by the developer based on subjective experiences. However, due to the insufficiency of the information, user requirements often cannot be accurately expressed, this ambiguity needs to apply an integrated approach to solve it.

\subsection{Determine the relative importance of user demands}

The number of user groups is supposed as K, and the total number of needs is supposed as $\mathrm{M}$ in the quality house, expressed as $W_{m}(m=1,2 \cdots M)$. And the 
number of construction companies is supposed as L, which has (l-1) competitors, expressed as: $C_{2}, C_{3} \cdots C_{L}$.

For the different user groups, the importance of these requirements is different, therefore, the relevant degrees between the demands are needed to identify. The importance of demand $m$ of the user groups $k$ is expressed as $\widetilde{g}_{m k}$, and then the average relative importance is expressed as

$\tilde{g}_{m}=\left(\tilde{g}_{m 1}+\tilde{g}_{m 2}+\cdots+\tilde{g}_{m k}\right) / K=\sum_{k=1}^{K} \tilde{g}_{m k} / K, \quad m=1,2 \cdots M$

As in Equation 1, $\tilde{g}_{m k}$ is expressed in symmetric fuzzy data [2], as shown in Table 1.

Table 1 Measure of judgment

\begin{tabular}{|c|c|}
\hline Define & Symmetric fuzzy judgement scales \\
\hline Equally important & {$[0,1,2]$} \\
\hline Somewhat important & {$[2,3,4]$} \\
\hline Important & {$[4,5,6]$} \\
\hline Much more important & {$[6,7,8]$} \\
\hline Absolutely essential & {$[8,9,10]$} \\
\hline
\end{tabular}

The execute ability of the company $L$ against the various demands is expressed as Matrix $M \times L$ :

$$
X=\begin{gathered}
C_{1} \\
W_{1} \\
W_{2} \\
\cdots \\
W_{M}
\end{gathered}\left[\begin{array}{cccc}
x_{11} & x_{12} & \cdots & x_{1 L} \\
x_{21} & x_{22} & \cdots & x_{2 L} \\
\cdots & \cdots & \cdots & \cdots \\
x_{M 1} & x_{M 2} & \cdots & x_{M L}
\end{array}\right]_{M \times L}
$$

The entropy is combined to determine relative importance of users ' demands [3].

$$
\begin{aligned}
& x_{m}=x_{m 1}+x_{m 2}+\cdots+x_{m L}, \quad m=1,2 \cdots M \\
& p_{m l}=x_{m l} / x_{m}, l=1,2 \cdots L, \quad m=1,2 \cdots M \\
& E\left(W_{m}\right)=-\phi_{L} \sum_{i=1}^{L} p_{m l} \ln \left(p_{m l}\right), \quad l=1,2 \cdots L, \quad m=1,2 \cdots M
\end{aligned}
$$

The priority levels of company for users requirements is expressed as

$$
e_{m}=E\left(W_{m}\right) / \sum_{m=1}^{M} E\left(W_{m}\right), \quad m=1,2 \cdots M
$$

In order to meet user demands the target values of the company $C_{1}$ is proposed as $a_{m}$. And under normal circumstances, target value is not less than the current company's ability to execute, and the improved capacity for the company $C_{1}$ is expressed as

$$
u_{m}=a_{m} / x_{m 1}, \quad m=1,2 \cdots M
$$

By focusing on the user groups, competing priorities, the improved capacity of the company that highly relevant to users ' demands, the final related degrees of the user demands can be drawn as follows:

$$
\tilde{f}_{m}=u_{m} \times \tilde{g}_{m} \times e_{m}, m=1,2 \cdots M, \tilde{f}_{m}=\left(\tilde{f}_{1}, \tilde{f}_{2} \cdots \tilde{f}_{M}\right)
$$

According the two kinds of user demands as $W_{1}, W_{2}, \tilde{f}_{1}=\left(b_{1}, d_{1}, c_{1}\right), \tilde{f}_{2}=\left(b_{2}, d_{2}, c_{2}\right)$, and the compare formula is drawn as follows:

$$
\mathrm{V}\left(W_{2}>W_{1}\right)=\left\{\begin{array}{cc}
1, & d_{2}>d_{1} ; \\
0, & c_{1}>b_{2} ; \\
\frac{b_{1}-c_{2}}{\left(d_{2}-c_{2}\right)-\left(d_{1}-b_{1}\right)}, & \text { other. }
\end{array}\right.
$$

\subsection{User demands are translate into the technical characteristics of building project}

Technical characteristics are expressed as $H_{n}(n=1,2 \cdots N)$, and the correlation matrix of users' demands and the technical characteristics of the building project are drawn as follows:

$$
\tilde{t}_{n}=\tilde{f}_{1} \times \tilde{r}_{1 n}+\tilde{f}_{2} \times \tilde{r}_{2 n}+\cdots+\tilde{f}_{M} \times \tilde{r}_{M n}=\sum_{m=1}^{M} \tilde{f}_{m} \times \tilde{r}_{M n}, n=1,2 \cdots N
$$

The technology priorities are expressed as $z_{n}$, and the capacity is expressed as a $v_{n}$, similarly, the Final grade is expressed as:

$$
\tilde{s}_{n}=v_{n} \times \tilde{t}_{n} \times z_{n}, \quad n=1,2 \cdots N
$$

According to the Equation 8, the final relationship between the technical characteristics can be drawn.

\section{APPLICATION EXAMPLES BASED ON QFD}

An example as the construction of CBD in a city is to illustrate the usefulness of the method.

\subsection{Importance analysis of CBD demands}

According to the CBD features, users are divided into: office workers $k_{1}$, residents $k_{2}$, service providers $k_{3}$ and customers $k_{4}$. And the demands of the CBD can be divided into 10 features: centrality $W_{1}$, accessibility $W_{2}$, service intensity $W_{3}$, interactive $W_{4}$, iconic $W_{5}$, internationalization $W_{6}$, digital $W_{7}$, human nature $W_{8}$, ecology $W_{9}$, and highly complex $W_{10}$ [4]. The importance degrees of demand characteristics from different users are different. The Delphi method is used, and these observations are collated and summarized, to get the initial importance of user requirements. According to the Equation 2, an average of relative importance is as shown in Table 2. 
Table 2 relative importance of user demands

\begin{tabular}{|c|c|c|c|c|c|}
\hline $\begin{array}{c}\text { Demand } \\
\text { characteristics }\end{array}$ & $\tilde{g}_{m 1}$ & $\tilde{g}_{m 2}$ & $\tilde{g}_{m 3}$ & $\tilde{g}_{m 4}$ & $\tilde{g}_{m}$ \\
\hline$W_{1}$ & {$[6,7,8]$} & {$[6,7,8]$} & {$[6,7,8]$} & {$[4,5,6]$} & {$[5.5,6.5,7.5]$} \\
\hline$W_{2}$ & {$[6,7,8]$} & {$[6,7,8]$} & {$[4,5,6]$} & {$[0,1,2]$} & {$[4,5,6]$} \\
\hline$W_{3}$ & {$[8,9,10]$} & {$[8,9,10]$} & {$[8,9,10]$} & {$[4,5,6]$} & {$[7,8,9]$} \\
\hline$W_{4}$ & {$[0,1,2]$} & {$[0,1,2]$} & {$[4,5,6]$} & {$[8,9,10]$} & {$[3,4,5]$} \\
\hline$W_{5}$ & {$[0,1,2]$} & {$[0,1,2]$} & {$[6,7,8]$} & {$[8,9,10]$} & {$[3.5,4.5,5.5]$} \\
\hline$W_{6}$ & {$[0,1,2]$} & {$[0,1,2]$} & {$[6,7,8]$} & {$[8,9,10]$} & {$[3.5,4.5,5.5]$} \\
\hline$W_{7}$ & {$[6,7,8]$} & {$[6,7,8]$} & {$[6,7,8]$} & {$[0,1,2]$} & {$[4.5,5.5,6.5]$} \\
\hline$W_{8}$ & {$[6,7,8]$} & {$[2,3,4]$} & {$[6,7,8]$} & {$[0,1,2]$} & {$[3.5,4.5,5.5]$} \\
\hline$W_{9}$ & {$[6,7,8]$} & {$[8,9,10]$} & {$[6,7,8]$} & {$[0,1,2]$} & {$[5,6,7]$} \\
\hline$W_{10}$ & {$[8,9,10]$} & {$[4,5,6]$} & {$[8,9,10]$} & {$[0,1,2]$} & {$[5,6,7]$} \\
\hline
\end{tabular}

Under the contract conditions, the company gets the rights of planning, design and implementation of the CBD by competition, and there are three finalists: $C_{1}, C_{2}$ and $C_{3}$. According to experts' evaluation, the implementation capacity, implementation priorities $e_{m}$ and improve skills $u_{m}$ of all units for a certain demand characteristics are as shown in Table 3 and Table4. And then according to Equation 7, the final relative importance of user demands are computed as shown in Table 5.

Table 4 Objectives and improved capacity

\begin{tabular}{|c|c|c|c|c|c|}
\hline \multirow{2}{*}{$\begin{array}{c}\text { Demand } \\
\text { characteristics }\end{array}$} & \multicolumn{3}{|c|}{\begin{tabular}{c} 
execute ability \\
\multirow{2}{*}{ compare }
\end{tabular}} & \multirow{2}{*}{$u_{m}=a_{m} / x_{m l}$} \\
\cline { 2 - 4 } & $C_{l}$ & $C_{2}$ & $C_{3}$ & & \\
\hline$W_{1}$ & 6 & 4 & 4.5 & 7 & 1.1667 \\
\hline$W_{2}$ & 5.5 & 4 & 7 & 7 & 1.2727 \\
\hline$W_{3}$ & 6 & 4 & 8 & 9 & 1.5000 \\
\hline$W_{4}$ & 3.5 & 2.5 & 3.5 & 7 & 2.0000 \\
\hline$W_{5}$ & 4 & 2.5 & 4 & 7 & 1.7500 \\
\hline$W_{6}$ & 4 & 3 & 2 & 7 & 1.7500 \\
\hline$W_{7}$ & 5.5 & 4 & 7.5 & 7 & 1.2727 \\
\hline$W_{8}$ & 5 & 3.5 & 6 & 9 & 1.8000 \\
\hline$W_{9}$ & 6 & 4 & 7 & 7 & 1.1667 \\
\hline$W_{10}$ & 4.5 & 3 & 6 & 7 & 1.5556 \\
\hline
\end{tabular}

Table 3 Competitiveness analysis of user demands

\begin{tabular}{|c|c|c|c|c|c|c|c|c|c|c|c|c|c|c|c|c|}
\hline \multirow{2}{*}{$\begin{array}{c}\text { Demand } \\
\text { characteristics }\end{array}$} & \multicolumn{3}{|c|}{$K_{I}$} & \multicolumn{3}{|c|}{$K_{2}$} & \multicolumn{3}{|c|}{$K_{3}$} & \multicolumn{3}{|c|}{$K_{4}$} & & & & \multirow[b]{2}{*}{$e_{m}$} \\
\hline & $C_{I}$ & $C_{2}$ & $C_{3}$ & $C_{I}$ & $C_{2}$ & $C_{3}$ & $C_{1}$ & $C_{2}$ & $C_{3}$ & $C_{1}$ & $C_{2}$ & $C_{3}$ & $C_{1}$ & $C_{2}$ & $C_{3}$ & \\
\hline$W_{1}$ & 5 & 3 & 5 & 5 & 3 & 5 & 7 & 5 & 3 & 7 & 5 & 5 & 6 & 4 & 4.5 & 0.1011 \\
\hline$W_{2}$ & 7 & 5 & 9 & 7 & 5 & 9 & 7 & 5 & 7 & 1 & 1 & 3 & 5.5 & 4 & 7 & 0.1001 \\
\hline$W_{3}$ & 7 & 5 & 9 & 7 & 5 & 9 & 7 & 5 & 9 & 3 & 1 & 5 & 6 & 4 & 8 & 0.0990 \\
\hline$W_{4}$ & 1 & 1 & 1 & 1 & 1 & 1 & 5 & 3 & 7 & 7 & 5 & 5 & 3.5 & 2.5 & 3.5 & 0.1014 \\
\hline$W_{5}$ & 1 & 1 & 1 & 1 & 1 & 1 & 7 & 3 & 7 & 7 & 5 & 7 & 4 & 2.5 & 4 & 0.1005 \\
\hline$W_{6}$ & 1 & 1 & 1 & 1 & 1 & 1 & 7 & 5 & 3 & 7 & 5 & 3 & 4 & 3 & 2 & 0.0990 \\
\hline$W_{7}$ & 7 & 5 & 9 & 7 & 5 & 9 & 7 & 5 & 9 & 1 & 1 & 3 & 5.5 & 4 & 7.5 & 0.0995 \\
\hline$W_{8}$ & 7 & 5 & 9 & 5 & 3 & 5 & 7 & 5 & 9 & 1 & 1 & 1 & 5 & 3.5 & 6 & 0.1003 \\
\hline$W_{9}$ & 7 & 5 & 9 & 9 & 5 & 9 & 7 & 5 & 9 & 1 & 1 & 1 & 6 & 4 & 7 & 0.1001 \\
\hline$W_{10}$ & 7 & 5 & 9 & 3 & 1 & 5 & 7 & 5 & 9 & 1 & 1 & 1 & 4.5 & 3 & 6 & 0.0990 \\
\hline
\end{tabular}

Table 5 Final related importance degrees

\begin{tabular}{|c|c|c|}
\hline $\begin{array}{c}\text { Demand } \\
\text { characteristics }\end{array}$ & $\tilde{f}_{m}$ & Standardization \\
\hline$W_{1}$ & {$[0.6487,0.7667,0.8847]$} & {$[0.4854,0.5737,0.6620]$} \\
\hline$W_{2}$ & {$[0.5096,0.6370,0.7644]$} & {$[0.3813,0.4766,0.5719]$} \\
\hline$W_{3}$ & {$[1.0395,1.1880,1.3365]$} & {$[0.7778,0.8889,1.0000]$} \\
\hline$W_{4}$ & {$[0.6084,0.8112,1.0140]$} & {$[0.4552,0.6070,0.7587]$} \\
\hline$W_{5}$ & {$[0.6155,0.7914,0.9673]$} & {$[0.4605,0.5921,0.7238]$} \\
\hline$W_{6}$ & {$[0.6064,0.7796,0.9529]$} & {$[0.4537,0.5833,0.7130]$} \\
\hline$W_{7}$ & {$[0.5699,0.6965,0.8231]$} & {$[0.4264,0.5211,0.6159]$} \\
\hline$W_{8}$ & {$[0.6319,0.8124,0.9930]$} & {$[0.4728,0.6079,0.7430]$} \\
\hline$W_{9}$ & {$[0.5839,0.7007,0.8175]$} & {$[0.4369,0.5243,0.6117]$} \\
\hline$W_{10}$ & {$[0.7700,0.9240,1.0780]$} & {$[0.5761,0.6914,0.8066]$} \\
\hline & & \\
\hline
\end{tabular}

Based on the above calculation results and according to Equation 8, the relationship between user requirements can be reached as: $W_{3}>W_{10}>\left\{W_{4}, W_{8}\right\}>W_{5}>\left\{W_{6}, W_{1}\right\}>\left\{W_{7}, W_{9}\right\}>W_{2}$, and the "> " is represented more important, the $\left\{W_{4}, W_{8}\right\}$ means for equally important.

\subsection{Conversion of CBD demands to Building Projects}

By the designers and builders, the demands are converted into achievable building projects, which Includes hotel $H_{1}$, casino $H_{2}$, shopping center $H_{3}$, municipal facilities $H_{4}$, writing office $H_{5}$, apartments $H_{6}$, food plaza $H_{7}$ and transportation facilities $H_{8}$ [5]. And the correlation of the demands and projects is computed as shown in Table 6.

According to Table 6 and Equation 9, the initial technical grade is counted. The same calculation is used, and the technical competitive analysis and final technical relevance are counted as shown in table 7. The account competitive factors are considered, and according to the Equation 10, the final building projects characteristics are computed as shown in table 8 .

According to the table and Equation 8, the relationship between construction projects of CBD can be obtained as follows: $H_{3}>\left\langle H_{5}, H_{2}, H_{7}\right\}>H_{1}>H_{6}>H_{8}>H_{4}$. Based on the above results, the conclusions are drawn are as follows: the first consideration is shopping center, followed by the writing office, the 
casino and the food plaza, in the CBD construction of a city. This result is the same with previous experience [6]. So user demands are implemented into the building projects, relationship between the technical characteristics was obtained, and the focus was stressed.

Table 6 Correlation matrix

\begin{tabular}{|c|c|c|c|c|c|c|c|c|}
\hline $\mathrm{R}$ & $H_{1}$ & $H_{2}$ & $H_{3}$ & $H_{4}$ & $H_{5}$ & $H_{6}$ & $H_{7}$ & $H_{8}$ \\
\hline$W_{1}$ & {$[4,5,6]$} & {$[6,7,8]$} & {$[8,9,10]$} & {$[6,7,8]$} & {$[6,7,8]$} & {$[6,7,8]$} & {$[8,9,10]$} & {$[4,5,6]$} \\
\hline$W_{2}$ & {$[2,3,4]$} & {$[2,3,4]$} & {$[2,3,4]$} & {$[0,1,2]$} & {$[4,5,6]$} & {$[6,7,8]$} & {$[8,9,10]$} & {$[6,7,8]$} \\
\hline$W_{3}$ & {$[6,7,8]$} & {$[8,9,10]$} & {$[8,9,10]$} & {$[6,7,8]$} & {$[4,5,6]$} & {$[4,5,6]$} & {$[6,7,8]$} & {$[4,5,6]$} \\
\hline$W_{4}$ & {$[2,3,4]$} & {$[6,7,8]$} & {$[8,9,10]$} & {$[6,7,8]$} & {$[4,5,6]$} & {$[4,5,6]$} & {$[4,5,6]$} & {$[4,5,6]$} \\
\hline$W_{5}$ & {$[4,5,6]$} & {$[4,5,6]$} & {$[8,9,10]$} & {$[2,3,4]$} & {$[2,3,4]$} & {$[4,5,6]$} & {$[8,9,10]$} & {$[6,7,8]$} \\
\hline$W_{6}$ & {$[6,7,8]$} & {$[6,7,8]$} & {$[8,9,10]$} & {$[6,7,8]$} & {$[8,9,10]$} & {$[6,7,8]$} & {$[4,5,6]$} & {$[4,5,6]$} \\
\hline$W_{7}$ & {$[4,5,6]$} & {$[2,3,4]$} & {$[8,9,10]$} & {$[6,7,8]$} & {$[0,1,2]$} & {$[0,1,2]$} & {$[4,5,6]$} & {$[2,3,4]$} \\
\hline$W_{8}$ & {$[6,7,8]$} & {$[2,3,4]$} & {$[6,7,8]$} & {$[4,5,6]$} & {$[4,5,6]$} & {$[0,1,2]$} & {$[0,1,2]$} & {$[0,1,2]$} \\
\hline$W_{9}$ & {$[6,7,8]$} & {$[2,3,4]$} & {$[2,3,4]$} & {$[2,3,4]$} & {$[0,1,2]$} & {$[0,1,2]$} & {$[0,1,2]$} & {$[8,9,10]$} \\
\hline$W_{10}$ & {$[2,3,4]$} & {$[0,1,2]$} & {$[4,5,6]$} & {$[2,3,4]$} & {$[8,9,10]$} & {$[8,9,10]$} & {$[4,5,6]$} & {$[6,7,8]$} \\
\hline
\end{tabular}

Table 7 competitive analysis, target and improve capacity

\begin{tabular}{|c|c|c|c|c|c|c|}
\hline \multirow{2}{*}{ projects } & \multicolumn{3}{|c|}{$\begin{array}{c}\text { competitive ability } \\
\text { compare }\end{array}$} & $z_{n}$ & $b_{n}$ & \multirow{2}{*}{$v_{n}$} \\
\cline { 2 - 7 } & $C_{1}$ & $C_{2}$ & $C_{3}$ & & & \\
\hline$H_{1}$ & 7 & 5 & 9 & 0.1245 & 9 & 1.2587 \\
\hline$H_{2}$ & 5 & 7 & 7 & 0.1263 & 7 & 1.4000 \\
\hline$H_{3}$ & 7 & 5 & 9 & 0.1245 & 9 & 1.2587 \\
\hline$H_{4}$ & 7 & 5 & 9 & 0.1245 & 7 & 1.0000 \\
\hline$H_{5}$ & 5 & 7 & 9 & 0.1245 & 7 & 1.4000 \\
\hline$H_{6}$ & 7 & 5 & 9 & 0.1245 & 9 & 1.2587 \\
\hline$H_{7}$ & 7 & 5 & 9 & 0.1245 & 9 & 1.2587 \\
\hline$H_{8}$ & 7 & 5 & 9 & 0.1263 & 7 & 1.0000 \\
\hline
\end{tabular}

Table 8 Final project grade

\begin{tabular}{|c|c|c|}
\hline projects & $\tilde{s}_{n}$ & Standardization \\
\hline$H_{1}$ & {$[4.5272,6.8437,9.6483]$} & {$[0.3512,0.5310,0.7485]$} \\
\hline$H_{2}$ & {$[4.6945,7.1816,10.2077]$} & {$[0.3642,0.5572,0.7919]$} \\
\hline$H_{3}$ & {$[6.6854,9.5434,12.8895]$} & {$[0.5187,0.7404,1.0000]$} \\
\hline$H_{4}$ & {$[3.2539,5.1843,7.1454]$} & {$[0.2524,0.4022,0.5544]$} \\
\hline$H_{5}$ & {$[4.7570,7.2707,10.3158]$} & {$[0.3691,0.5641,0.8003]$} \\
\hline$H_{6}$ & {$[4.1301,6.3646,9.0872]$} & {$[0.3204,0.4938,0.7050]$} \\
\hline$H_{7}$ & {$[4.9055,7.3058,10.1940]$} & {$[0.3806,0.5668,0.7909]$} \\
\hline$H_{8}$ & {$[3.6366,5.4817,7.7118]$} & {$[0.2821,0.4253,0.5983]$} \\
\hline
\end{tabular}

\section{SUMMARY}

The Central Business District (CBD) is the core function of a city, and is an important symbol of a modern metropolis. From the perspective of economic developments in the major cities, CBD does become engines of regional economic development, promotes the region as a whole to enhance strength. However, it cannot be ignored that the construction, development and operation of central business district were just at the initial stage, and there was lack of experience in local government and the development of enterprise and carrier. They are prone to many problems, for example duplicate construction projects, features outstanding balance, the project does not balance, and the driving is not obvious. For the central business district, it directly determines its success or failure, how to analyze and Determine the functional requirements, how to carry out systematic and scientific professional planning, and how to get noticed and business atmosphere.

Through the QFD model based on entropy, the incomplete information and uncertainty were considered and addressed in the project's requirements analysis process of CBD building projects. By this method, users ' demands can be fully taken into account, and the relationship between indicators can be accurately revealed. It is conducive to prioritize the development and grasp the key point. It provides a very good idea of analysis and positioning for CBD features, and it is conducive to the construction and operation of the projects, eventually leading to economic prosperity for the city and region.

\section{REFERENCES}

[1] Dikmen, Irem, M. Talat Birgonul, and Semiha Kiziltas. "Strategic use of quality function deployment (QFD) in the construction industry." Building and Environment 40.2 (2005): 245-255.

[2] Ayağ, Zeki, Funda Samanlioglu, and Gülçin Büyüközkan. "A fuzzy QFD approach to determine supply chain management strategies in the dairy industry." Journal of Intelligent Manufacturing 24.6 (2013): 1111-1122.

[3] Büyüközkan, Gülçin, and Gizem Çifçi. "An integrated QFD framework with multiple formatted and incomplete preferences: A sustainable supply chain application." Applied Soft Computing 13.9 (2013): 3931-3941.

[4] Suhong LIU. Y. YAN. X. "Analysis and Comparison of the CBD Study between Domestic China and Overseas." Urban Planning Forum. Vol. 1. (2007):1-7.

[5] Murphy, Raymond E., James E. Vance, and Bart J. Epstein. "Internal Structure of the CBD." Economic Geography (1955): 21-46.

[6] Shou-mei, LUO Fu-yuan LUO. "Retrospect and prospect of the domestic CBD study from the 1980S." Urban Problems 6 (2004): 003. 